\title{
LA-UR-18-31137
}

Approved for public release; distribution is unlimited.

Title: $\quad$ Fiscal Year (FY) 2018 Activities for the Non-invasive acoustic monitoring of D2O concentration Project

Author(s): $\quad$ Pantea, Cristian

Beedle, Christopher Craig

Lakis, Rollin Evan

Intended for: $\quad$ Report

Issued:

2018-11-28 
Disclaimer:

Los Alamos National Laboratory, an affirmative action/equal opportunity employer, is operated by Triad National Security, LLC for the National Nuclear Security Administration of U.S. Department of Energy under contract 89233218CNA000001. By approving this article, the publisher recognizes that the U.S. Government retains nonexclusive, royalty-free license to publish or reproduce the published form of this contribution, or to allow others to do so, for U.S. Government purposes. Los Alamos National Laboratory requests that the publisher identify this article as work performed under the auspices of the U.S. Department of Energy. Los Alamos National Laboratory strongly supports academic freedom and a researcher's right to publish; as an institution, however, the Laboratory does not endorse the viewpoint of a publication or guarantee its technical correctness. 


\section{Fiscal Year (FY) 2018 Activities for the Non-invasive acoustic monitoring of $\mathrm{D}_{2} \mathrm{O}$ concentration Project}

By Cristian Pantea, Christopher Beedle, and Rollin Lakis, Los Alamos National Laboratory

Abstract: The main focus of research in the NA-241 $\mathrm{D}_{2} \mathrm{O}$ nondestructive assay (NDA) project in FY18 has been developing a portable on-site inspection tool. Additionally, the data acquisition part of a userfriendly software interface was developed.

\section{Introduction}

Current methods for H/D determination require periodic sampling and analysis. This approach does not provide the opportunity for persistent monitoring and verification by the IAEA and is relatively expensive and inefficient compared to the potential implementation of real-time, online verification by acoustic methods. Acoustic methods may provide a simpler solution, and can lead to better resolution. Additional, these methods require only modest electronics (already demonstrated for other metering applications) and reliable electrical connections. This is a significant enhancement over electromanometer techniques. We are working on an approach that can lead to a precision and accuracy of better than $\pm 0.2 \%$, volumetric.

Portable on-site inspection tool development In FY18 we worked on two representative types of storage forms: (1) 50 liter Stainless Steel SCHÄFER keg, and (2) portable sampling cell. While we intended initially to focus on process pipes, drums, and/or tank walls, the portable sampling cell was strongly suggested as the main interest by IAEA and NA-241.

(1) 50 liter Stainless Steel SCHÄFER keg Instrumented a heavy water storage keg with different acoustic transducers, see Figure 1 below.

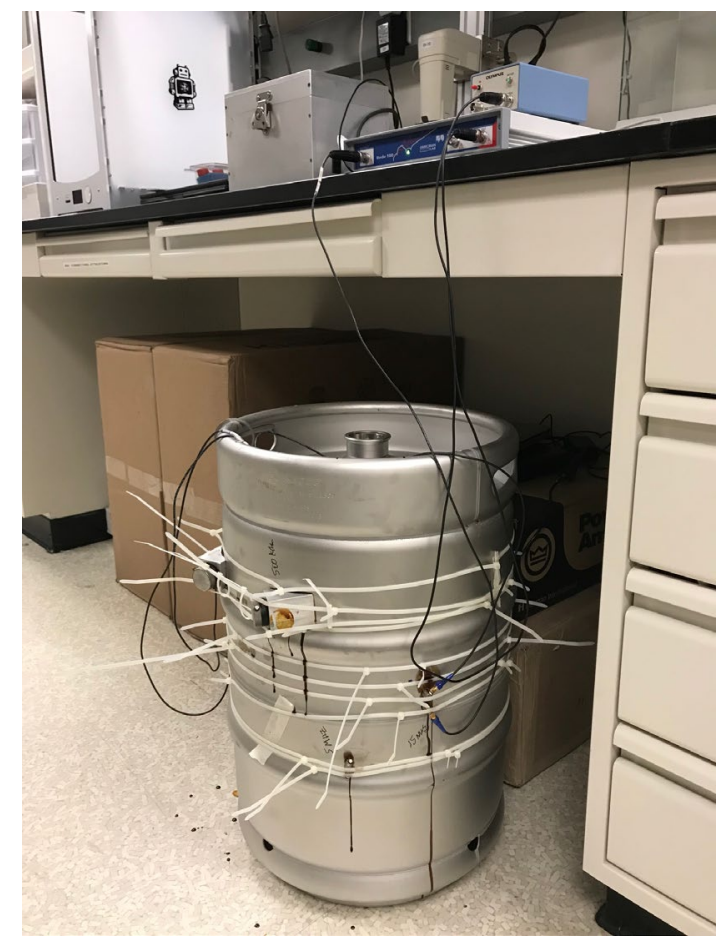

Figure 1. Instrumented heavy water storage keg. 
Tested extensively different approaches for transducers placement and measurement technique for the 50 liter Stainless Steel SCHÄFER keg. Settled on a single transducer approach (2-5 MHz), taking advantage of the presence of the steel pipe in the middle, and performing reflection measurements.

Still working on a simple clamp-on system, and performing additional measurements to streamline the data acquisition.

(2) Portable sampling cell

Built the first version of the portable sampling cell, see picture in Figure 2. Main components: sampling cell, transducer pair for acoustic measurements, magnetic stir system, thermal insulation, thermistors for temperature measurements.

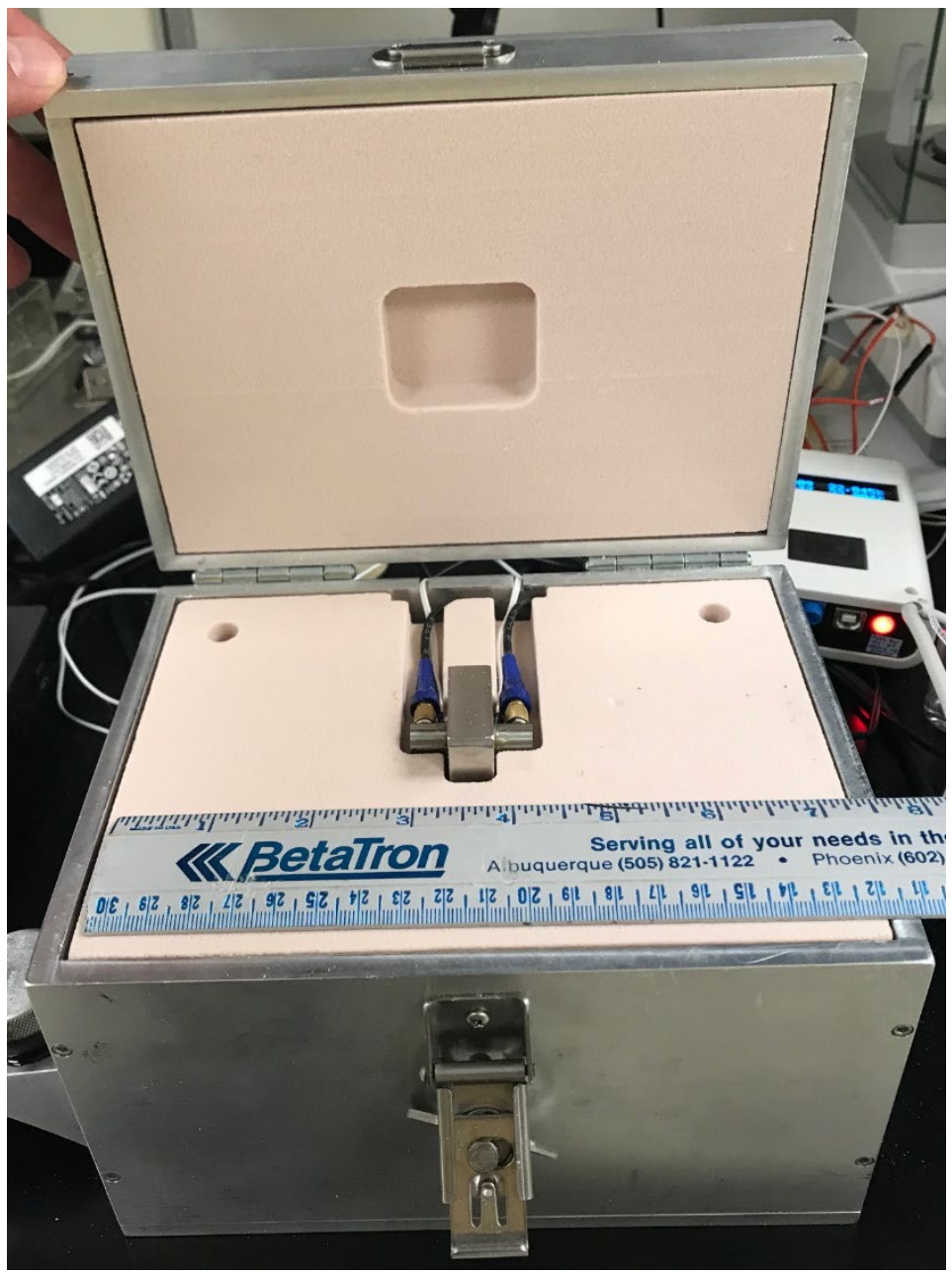

Figure 2. First version of the portable sampling cell system.

Data collected in the new sampling cell are in good agreement with existing calibration data. Working on setting up a live demonstration for NA241 office. The following was defined as deliverable: 'Portable tool functionality demonstrated in the laboratory (end of FY18)'. While the full development is expected to take two years, an intermediate deliverable was defined to ensure that the team is on-track with the development of the portable tool. 
User-friendly software interface development

In FY 18 we worked on the development of a user-friendly Graphical User Interface (GUI) in LabView, for data acquisition. The data analysis part postponed to FY19, as only partial funding was received for software development (received $\$ 50 \mathrm{~K}$ out of the $\$ 185 \mathrm{~K}$ needed for full development). A snapshot of the GUI is shown in Figure 3. Needs additional work, including simplification of the front panel and development and implementation of data analysis code.

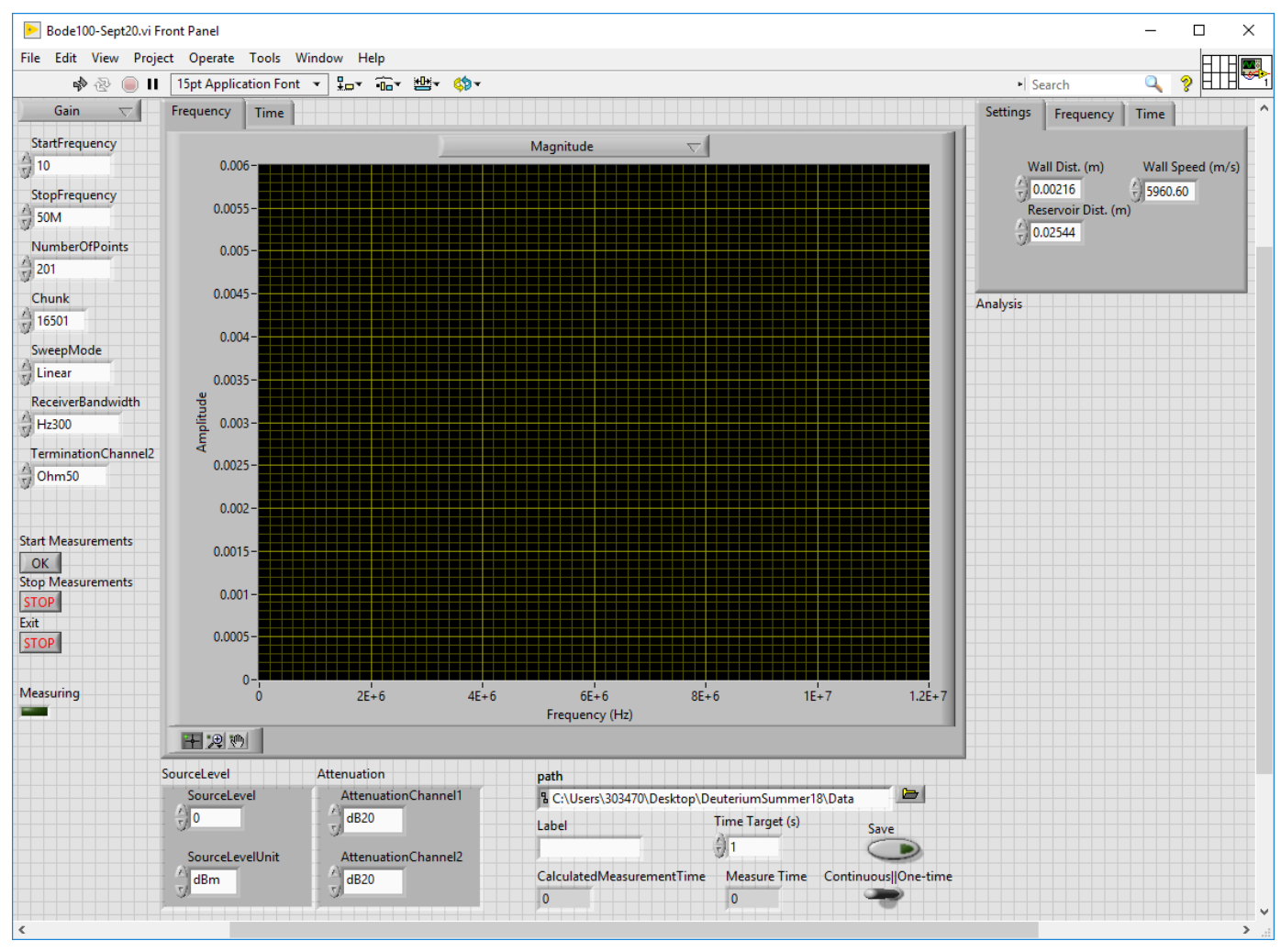

Figure 3. Data acquisition GUI (Graphical User Interface).

During July 11-13, 2018, the PI (Cristian Pantea) travelled to Joint Research Center in Ispra, Italy, to participate in the 2018 Joint Steering Committee (JSC) Meetings between the United States Department of Energy (DOE) and the European Atomic Energy Community (Euratom) represented by the European Commission. The purpose of his trip was to present heavy water monitoring results for a possible upcoming field trial. 


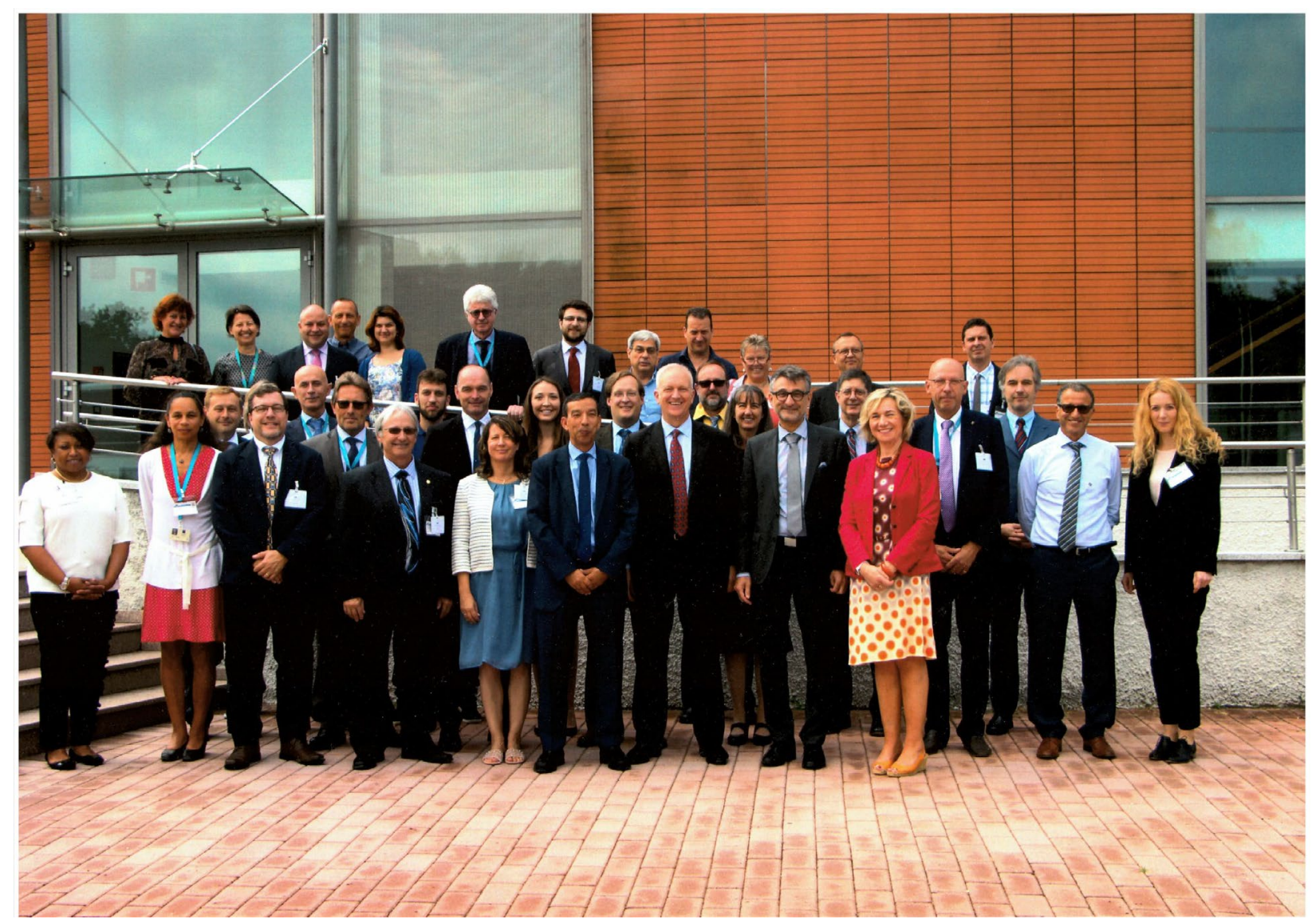

